\section{Establishing the risk of neonatal mortality using a fuzzy predictive model}

\author{
Modelo preditivo fuzzy para estabelecer o risco \\ de morte neonatal
}

\section{${ }_{1}^{1}$ Departamento de Medicina, Universidade de Taubaté, \\ Taubaté, Brasil. \\ 2 Faculdade de Engenharia de Guaratinguetá, Universidade Estadual Paulista, \\ Guaratinguetá, Brasil. 3 Instituto Tecnológico de Aeronáutica,-São José dos Campos, Brasil. \\ Correspondence L. F. C. Nascimento Departamento de Medicina Universidade de Taubaté. Rua Durval Rocha 500, Guaratinguetá, SP 12515-710, Brasil. lfcn@unitau.br} \section{The objective of this study was to develop a fuzzy
model to estimate the possibility of neonatal
mortality. A computing model was built, based
on the fuzziness of the following variables: new-
born birth weight, gestational age at delivery,
Apgar score, and previous report of stillbirth.
The inference used was Mamdani's method and
the output was the risk of neonatal death given
as a percentage. 24 rules were created accord-
ing to the inputs. The validation model used a
real data file with records from a Brazilian city.
The receiver operating characteristic (ROC) curve The receiver operating characteristic (ROC) curve}

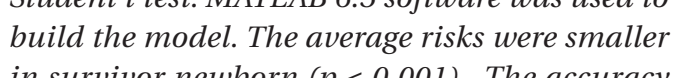
in survivor newborn $(p<0.001)$. The accuracy of the model was 0.90. The higher accuracy occurred with risk below 25\%, corresponding to 0.70 in respect to sensitivity, 0.98 specificity, 0.99 negative predictive value and 0.22 positive predictive value. The model showed a good accuracy, as well as a good negative predictive value and could be used in general hospitals.

Neonatal Mortality; Fuzzy Logic; Medical Informatics Computing; Risk Factors; Predictive Value of Tests
\end{abstract}


ously depressed when the Apgar score is below seven and previous reports of stillbirth are important causes of neonatal mortality.

The incidences of low birth weight and preterm newborn in Brazil are around 7\% (Department for Informatics at the Unified National Health System. http://tabnet.datasus.gov.br/ cgi/tabcgi.exe?sinasc/cnv/nvuf.def, accessed on 14/Jun/2007). Neonatal mortality in the State of Sao Paulo, the most industrialized state in Brazil, was 9.89/1,000 livebirths in 2004 (Department for Informatics at the Unified National Health System. http://tabnet.datasus.gov.br/cgi/tabcgi. exe?sim/cnv/infuf.def, accessed on 14/Jun/2007).

The estimate of risk of neonatal death can provide important information to pediatricians, especially to neonatal intensive care physicians, with respect to the attention a newborn requires. It is evident that the care provided to a newborn infant will differ depending on the hospital and its location. In fairly small hospitals it is common for there to be no pediatrician present at the time of birth, and other professionals are in charge of evaluating the newborn 5 .

To estimate the risk of neonatal death, a Regression Model using dichotomous independent variables such as Yes or No, Present or Absent has been applied 7. Fuzzy Logic allows assigning, for instance, a newborn with birth weight of 2,350g to a fuzzy subset low birth weight with 0.63 membership degree and to a normal birth weight fuzzy subset with 0.25 membership degree, taking into account the inherent uncertainties of this record. In fact, a newborn weighing $2,490 \mathrm{~g}$ at birth and another weighing $2,510 \mathrm{~g}$ at birth, who are classically categorized as low birth weight and normal birth weight respectively, do not show significant differences across biological, anatomical and physiological aspects. In the fuzzy approach each element may be compatible with several categories, with different membership degrees. The advantage of the fuzzy theory is to consider an even and more realistic classification of the children relating to the two variables assumed 5 .

The theory of fuzzy sets was introduced by Lotfi A. Zadeh in the 1960s as a means to model the uncertainty within natural language and introduced the concept of vagueness. According to this alternative view, uncertainty is considered essential to science. To the reader who wishes to learn more about fuzzy logic theory the book by Yen \& Langari 8 is recommended.

Thus, a theoretical fuzzy linguistic model is presented in the study, which is a low cost program able to evaluate more appropriately the risk of neonatal death based on birth weight, gestational age, Apgar score and previous report of stillbirth.

\section{Methods}

A computational model is used with a fuzzy linguistic model to evaluate the risk of neonatal death. This model involves four previously named inputs: birth weight, gestational age, Apgar score and previous report of stillbirth. The model was developed from one expert knowledge, who elaborated three fuzzy sets to the variable birth weight: very low birth weight, low birth weight, normal birth weight; and two fuzzy sets to the variable gestational age: preterm and term; and two fuzzy sets to the variable Apgar Score: Low, when the values were below seven, and high when the values are above eight; and two fuzzy sets to the variable previous report of stillbirth: few if there were zero or one stillbirth and many if there were two or more stillbirth. The output is the death risk with five linguistic labels: very high, high, middle high, middle and low. These fuzzy sets were built by fuzzying the classical pediatrics classification. Situations such as small to gestational age, adequate to gestational age and large to gestational age were not considered in this study.

A fuzzy linguistic model is a rule-based system that uses fuzzy sets theory to address the issue. Its basic structure includes four main components, as shown in Figure 1:

- A fuzzifier, which translates crisp inputs (classical numbers) into fuzzy values;

- An inference engine that applies a fuzzy reasoning mechanism to obtain a fuzzy output (in the case of Mamdani inference);

- A knowledge base, which contains both a set of fuzzy rules and a set of membership functions representing the fuzzy sets of the linguistic variable; and

- A defuzzifier, which translates the fuzzy output into a crisp value.

The decision process is performed by the inference engine using the rules contained in the rule base. These fuzzy rules define the connection between fuzzy input and output. A fuzzy rule has a form: if antecedent then consequent, where antecedent is a fuzzy expression composed of one or more fuzzy sets connected by fuzzy operators, and consequent is an expression that assigns fuzzy values to the output variables. The inference process evaluates all rules in the rule base and combines the weighted consequents of all relevant rules into a single output fuzzy set (Mamdani's model). The fuzzy output set may then be replaced by a "crisp" output value obtained by a process called defuzzification 8 .

The base rules are give in Table 1 . When a newborn is very low birth weight and is preterm and Apgar is low and previous report of stillbirth 


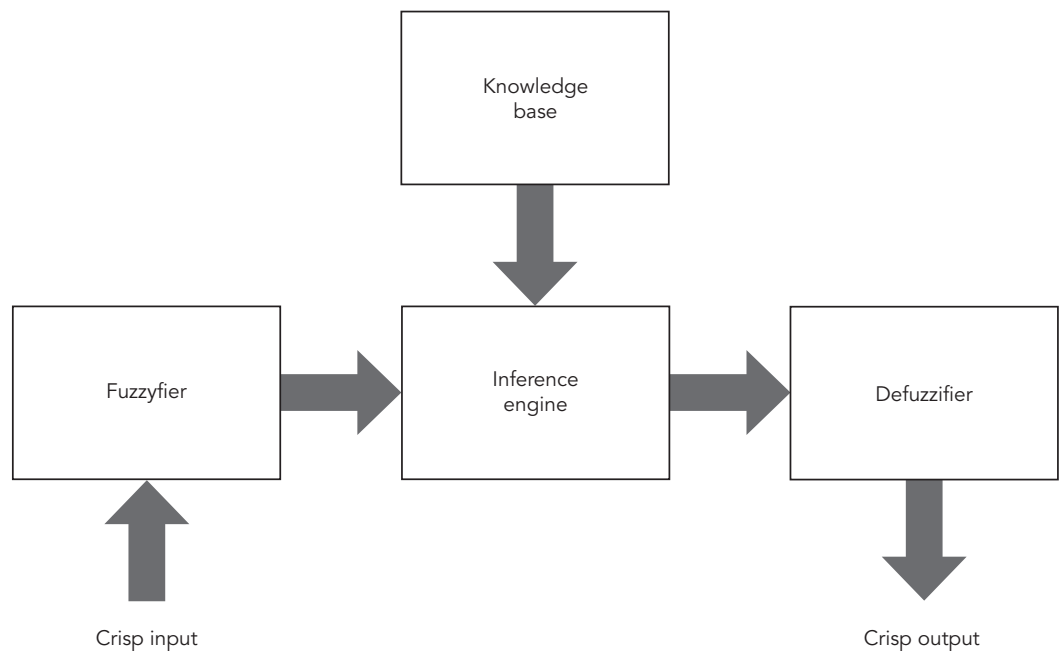

is few, then the risk of neonatal death is very high as shown by rule 1 . Note that the sequence of input is: birth weight; gestational age; Apgar score; previous report of stillbirth; and the output is risk of neonatal death, after the step named defuzzification. Centroid was the defuzzification method used in this study and the risk of neonatal death was estimated as a percentage.

Note that, by combining all possible inputs, it is possible to build 24 rules. The procedure of the fuzzy linguistic model, given four of the above inputs for any child, consists of calculating the membership degree of these values in all fuzzy sets of birth weight, gestational age, Apgar Score and previous report of stillbirth. Next, the risk of neonatal death is determined by inference of the fuzzy rule set, using Mamdani's inference and $d e$ fuzzification of the fuzzy output.

The fuzzy sets related to the linguistic variables birth weight, Apgar score, previous report of stillbirth and gestational age are presented in Figure 2.

This model was validated by using a real data set which contains the same variables of the defined fuzzy set. The real data set was taken from São José dos Campos, a mid-sized city in the Southeast of Brazil, in 2003. This data file contained information from the Brazilian Birth Certificate, an official document necessary for civil registration. This data file contained information about the newborn's situation up to 28 days of life - dead or alive. The accuracy of the model was estimated by the ROC (receiver operating characteristic) curve and the risk values were evaluated using the Student $t$ test. The Median test or Mann-Whitney test were used if the value of the risk did not have a normal distribution. The MATLAB software (MathWorks, Natick, USA) was used to perform the simulation.

\section{Results}

There were 58 neonatal deaths in 1,351 records. The mean value of the risk values was $9.85 \%$ $(\mathrm{SD}=14.02)$, the range of these values was 4.67 $90.33 \%$ and the median value was $4.67 \%$. The risk values do not have a normal distribution by using a Kolmogorov-Smirnov Test $(\mathrm{z}=5.47, \mathrm{p}<$ 0.001). The Mann Whitney resulted in a mean rank of $1,194.01$ to neonatal death and 652.76 to live newborn $(\mathrm{z}=-14.79, \mathrm{p}<0.001)$. The median test resulted in 49 neonatal deaths with risk value above the median (4.67\%) and 1,071 live newborns with risk value equal to or below the me$\operatorname{dian}\left(\chi^{2}=152.7, \mathrm{p}<0.001\right)$.

Figure 3 shows the membership functions of the output variable risk of neonatal death. The surface of the neonatal death risk using the gestational age and birth weight (in grams) and Apgar score and birth weight (in grams) are shown in Figure 4. 
Fuzzy rules of the model.

\begin{tabular}{|c|c|}
\hline 1 & If (BW is VLBW) and (GA is PT) and (APG is $L$ ) and (SB is F) then (Risk is VH) (1) * \\
\hline 2 & If (BW is VLBW) and (GA is PT) and (APG is $L$ ) and (SB is M) then (Risk is VH) (1) \\
\hline 3 & If (BW is VLBW) and (GA is PT) and (APG is $H$ ) and ( $\mathrm{SB}$ is F) then (Risk is $\mathrm{MH}$ ) (1) \\
\hline 4 & If (BW is VLBW) and (GA is PT) and (APG is $H$ ) and (SB is M) then (Risk is $H$ ) (1) \\
\hline 5 & If (BW is VLBW) and (GA is T) and (APG is $L$ ) and (SB is F) then (Risk is $H$ ) (1) \\
\hline 6 & If (BW is VLBW) and (GA is T) and (APG is $L$ ) and (SB is $M$ ) then (Risk is $H$ ) (1) \\
\hline 7 & If (BW is VLBW) and (GA is T) and (APG is $H$ ) and (SB is F) then (Risk is M) (1) \\
\hline 8 & If (BW is VLBW) and (GA is $T$ ) and (APG is $H$ ) and (SB is M) then (Risk is MH) (1) \\
\hline 9 & If (BW is $L B W$ ) and (GA is PT) and (APG is $L$ ) and ( $S B$ is F) then (Risk is $M H)$ (1) \\
\hline 10 & If (BW is $L B W$ ) and (GA is PT) and (APG is $L$ ) and (SB is $M$ ) then (Risk is $H$ ) (1) \\
\hline 11 & If (BW is LBW) and (GA is PT) and (APG is $H$ ) and ( $S B$ is F) then (Risk is M) (1) \\
\hline 12 & If (BW is $L B W$ ) and (GA is PT) and (APG is $H)$ and (SB is $M$ ) then (Risk is $M H)$ (1) \\
\hline 13 & If (BW is $L B W$ ) and (GA is $T$ ) and (APG is $L$ ) and (SB is F) then (Risk is $M H)$ (1) \\
\hline 14 & If (BW is $L B W$ ) and (GA is $T$ ) and (APG is $L$ ) and (SB is $M$ ) then (Risk is $M H)$ (1) \\
\hline 15 & If (BW is $L B W$ ) and (GA is $T$ ) and (APG is $H$ ) and (SB is F) then (Risk is $M$ ) (1) \\
\hline 16 & If (BW is $L B W$ ) and (GA is $T$ ) and (APG is $H$ ) and (SB is M) then (Risk is $M H)$ (1) \\
\hline 17 & If (BW is NBW) and (GA is PT) and (APG is $L$ ) and (SB is F) then (Risk is $M$ ) (1) \\
\hline 18 & If (BW is NBW) and (GA is PT) and (APG is $L$ ) and (SB is M) then (Risk is MH) (1) \\
\hline 19 & If (BW is NBW) and (GA is PT) and (APG is $H$ ) and (SB is F) then (Risk is M) (1) \\
\hline 20 & If (BW is NBW) and (GA is PT) and (APG is $H$ ) and (SB is $M$ ) then (Risk is $M$ ) (1) \\
\hline 21 & If (BW is NBW) and (GA is T) and (APG is $L$ ) and (SB is F) then (Risk is M) (1) \\
\hline 22 & If (BW is NBW) and (GA is T) and (APG is $L$ ) and (SB is $M$ ) then (Risk is M) (1) \\
\hline 23 & If (BW is NBW) and (GA is $T$ ) and (APG is $H$ ) and (SB is F) then (Risk is $L$ ) (1) \\
\hline 24 & If (BW is NBW) and (GA is $T$ ) and (APG is $H$ ) and (SB is M) then (Risk is $L$ ) (1) \\
\hline
\end{tabular}

Legend: BW: birth weight (VLBW: very low birth weight; LBW: low birth weight; NBW: normal birth weight); GA: gestational age (PT: preterm; T: term); APG: Apgar score (L: low; H: high); SB: previous report of stillbirth (F: few; M: many); Risk (VH: very high; $\mathrm{MH}$ : middle high; $\mathrm{H}$; high; $\mathrm{M}$ : middle; L: low).

* Where (1) is the weight of each rule that can range from 0 to 1 .

It can be noted in this graph that the risk of neonatal death decreases monotonically when birth weight or gestational age increases, as expected, such as higher Apgar score (Apgar score vs. birth weight).

In order to validate the computational model created, six dates were taken from the real data set with the following inputs: birth weight; gestational age; Apgar score; previous report of stillbirth. The output (risk of neonatal death) was given by the model.

Consider, for example, a newborn with birth weight of 3,500g, gestational age of 38 weeks, Apgar score of 5 and previous report of stillbirth of 0 . With these four antecedents the following membership functions were activated: normal birth weight for the variable birth weight; term to the variable gestational age, low to the variable
Apgar score, few to the variable previous report of stillbirth. The rule 21 was activated and the output variable activated was middle. After the defuzzification through the method centroid the result of the system (risk) is $25 \%$.

Below are presented other examples:

- Birth weight of 3,500, gestational age of 38 weeks, Apgar of 9, previous report of stillbirth of 0. Risk: $4.7 \%$.

- $\quad$ Birth weight of 1,500 , gestational age of 38 weeks, Apgar of 9, previous report of stillbirth of 0. Risk: $25 \%$.

- Birth weight of 1,500 , gestational age of 32 weeks, Apgar of 9, previous report of stillbirth of 0 . Risk: $35.5 \%$.

- $\quad$ Birth weight of 1,500 , gestational age of 32 weeks, Apgar of 5, previous report of stillbirth of 0. Risk: $65.5 \%$. 
Input membership functions.

2a)

Membership funcion plots

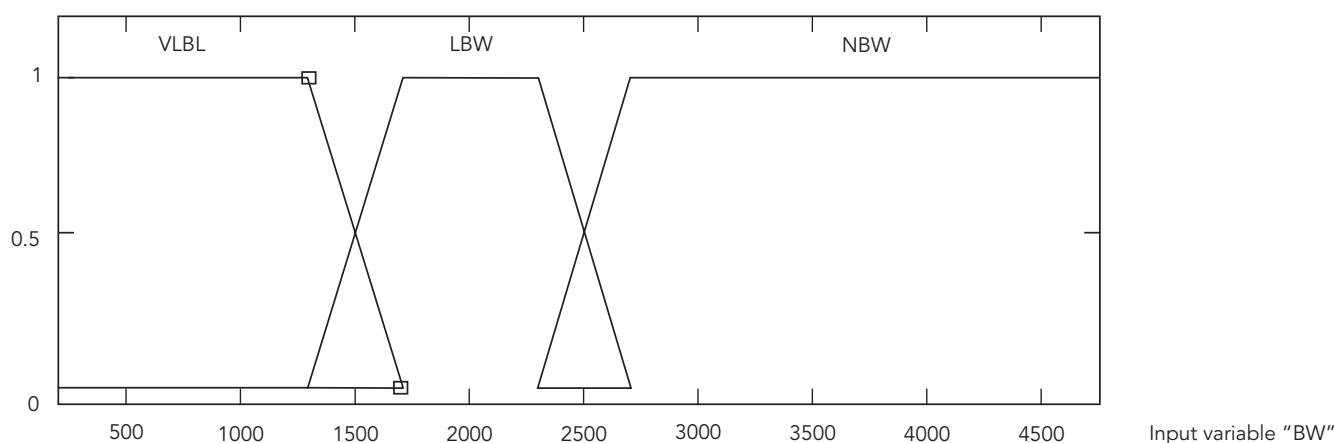

2b)

Membership funcion plots

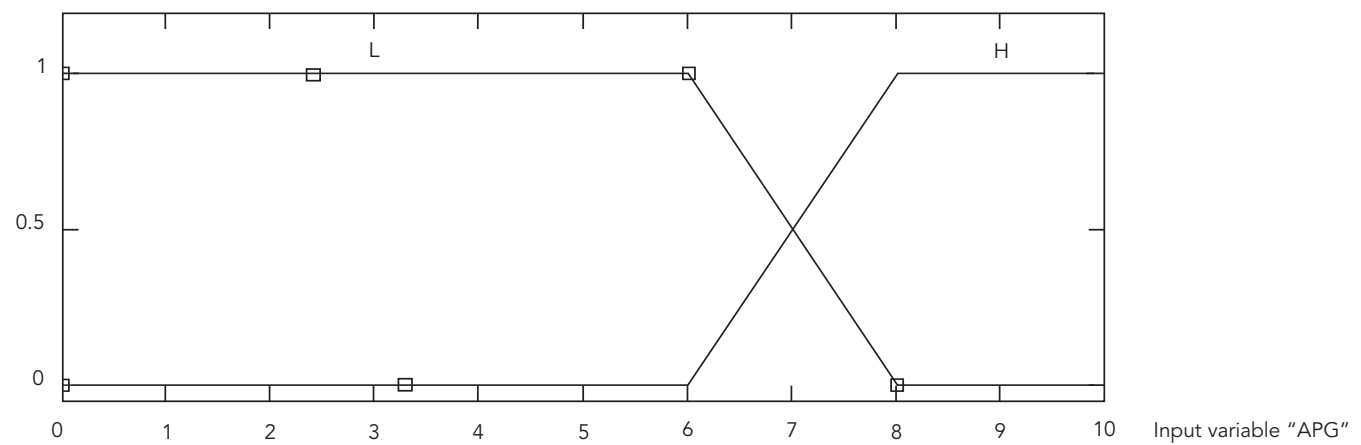

(continues)

- $\quad$ Birth weight of 1,500 , gestational age of 32 weeks, Apgar of 9, previous report of stillbirth of 0. Risk: $35.3 \%$.

- Birth weight of 1,500 , gestational age of 32 weeks, Apgar of 5, previous report of stillbirth of 2. Risk: $79.5 \%$.

In the first two cases both newborns survived.

Accuracy is higher when risk is below 25\%, corresponding to 0.70 in respect to sensitivity, 0.98 specificity, 0.99 negative predictive value and 0.22 positive predictive value. Considering $4.7 \%$ risk values, we obtained 0.82 in respect to sensitivity, 0.82 specificity, 0.99 negative predictive value and 0.16 positive predictive value. The
ROC curve is shown in Figure 5; the area under the curve is 0.90 (95\%CI: 0.84-0.96) $(\mathrm{p}<0.001)$.

\section{Discussion}

In this study, a fuzzy linguistic model to evaluate the risk of neonatal death based on birth weight, gestational age, Apgar score and previous report of stillbirth was proposed.

This study is not an epidemiological study about neonatal mortality; it aimed to build a computational predictive model by using fuzzy logic.

Neonatal mortality is a main component of childhood mortality (SUS Information Depart- 
2c)

Membership funcion plots

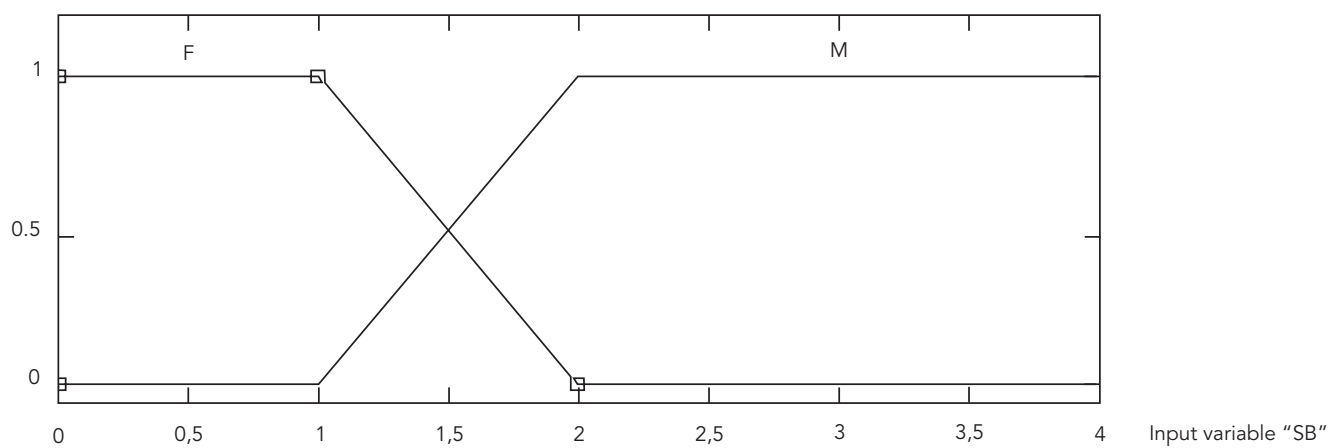

Membership funcion plots

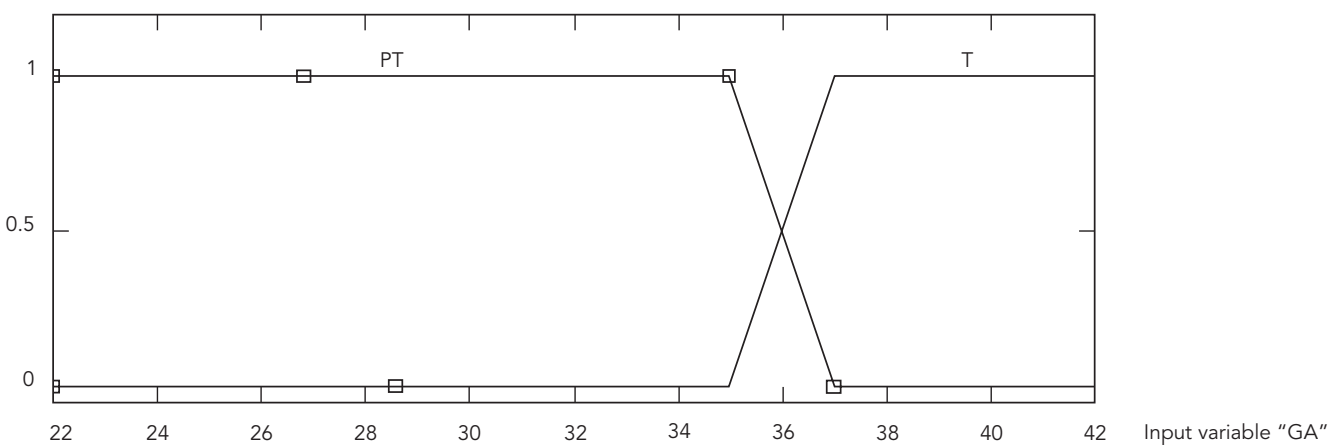

ment. http://tabnet.datasus.gov.br/cgi/tabcgi. exe?sim/cnv/infuf.def, accessed on 14/Jun/2007). The means of identifying newborns with high risk to neonatal mortality can offer information to physicians who attend these newborns to take actions and prevent devastating outcomes.

There are several methods to estimate the risk of neonatal death. The most commonly used methods are Pediatric Risk of Mortality (PRISM) 9 , the Score for Neonatal Acute Physiology (SNAP) 10 and the Clinical Risk for Index Baby (CRIB) 11.

These scores use several variables and several measures of blood analysis while newborns are interned in neonatal intensive care units. Besides, the accuracies obtained by the ROC curve of these studies were 0.90 in respect to CRIB and 0.92 in respect to PRISM.
Furthermore, other predictive models need a considerable number of records to establish an association between the outcome, neonatal death, and determinant variables, such as birth weight, Apgar score, previous report of stillbirth and gestational age, which is not necessary in the fuzzy model. Other approaches like artificial neural networks or neurofuzzy need records to train, check and validate the model. The model presented here provided good results as shown in the ROC curve.

The advantage of the risk estimator presented here is that model values cannot change over time, which is not true for experts' opinions. In fact, the experts could provide different values for death risk under the same conditions, depending on their positive or negative feelings and also 
Output membership function.

Membership funcion plots

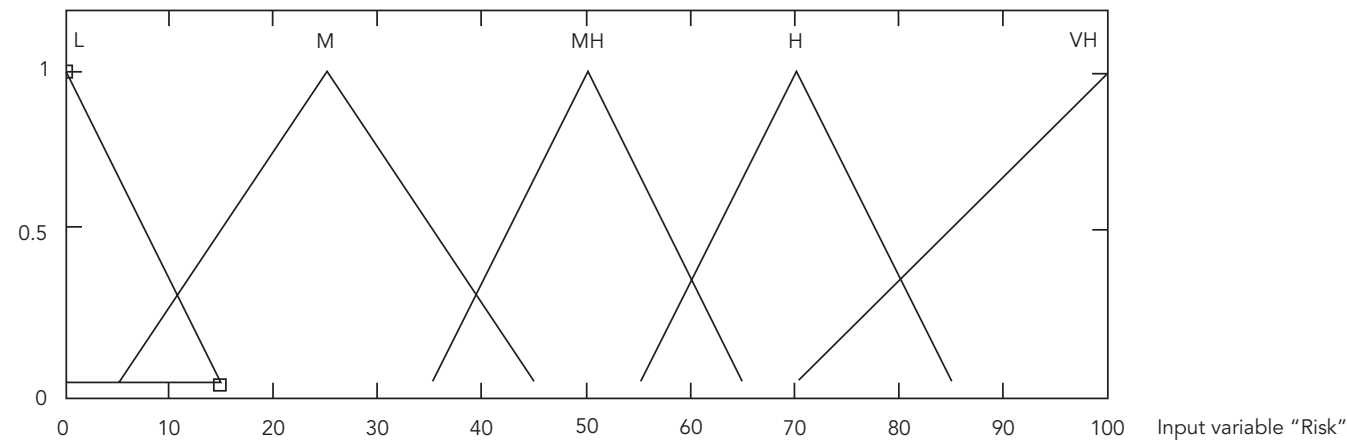

Figure 4

Surface of the risk of neonatal death relative to gestational age vs. birth weight and Apgar score vs. birth weight.

4a)

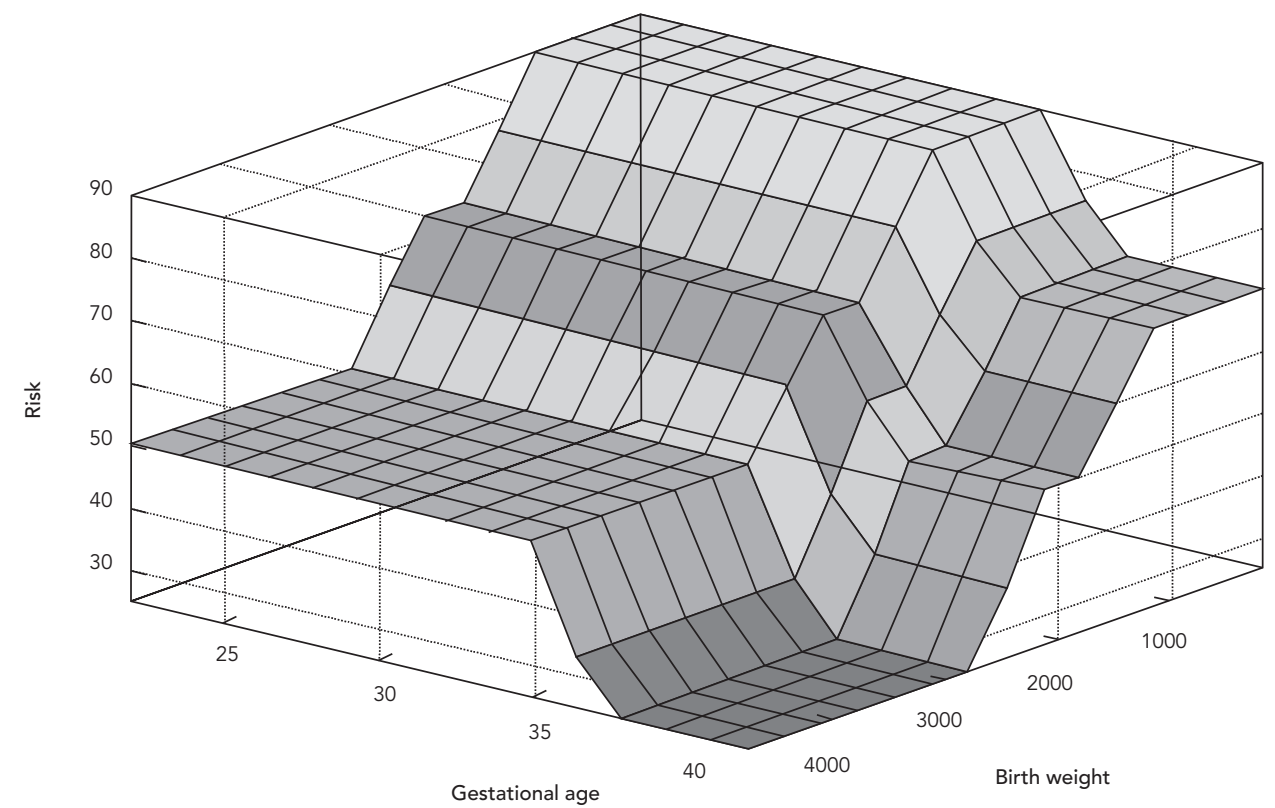

(continues) 
4b)

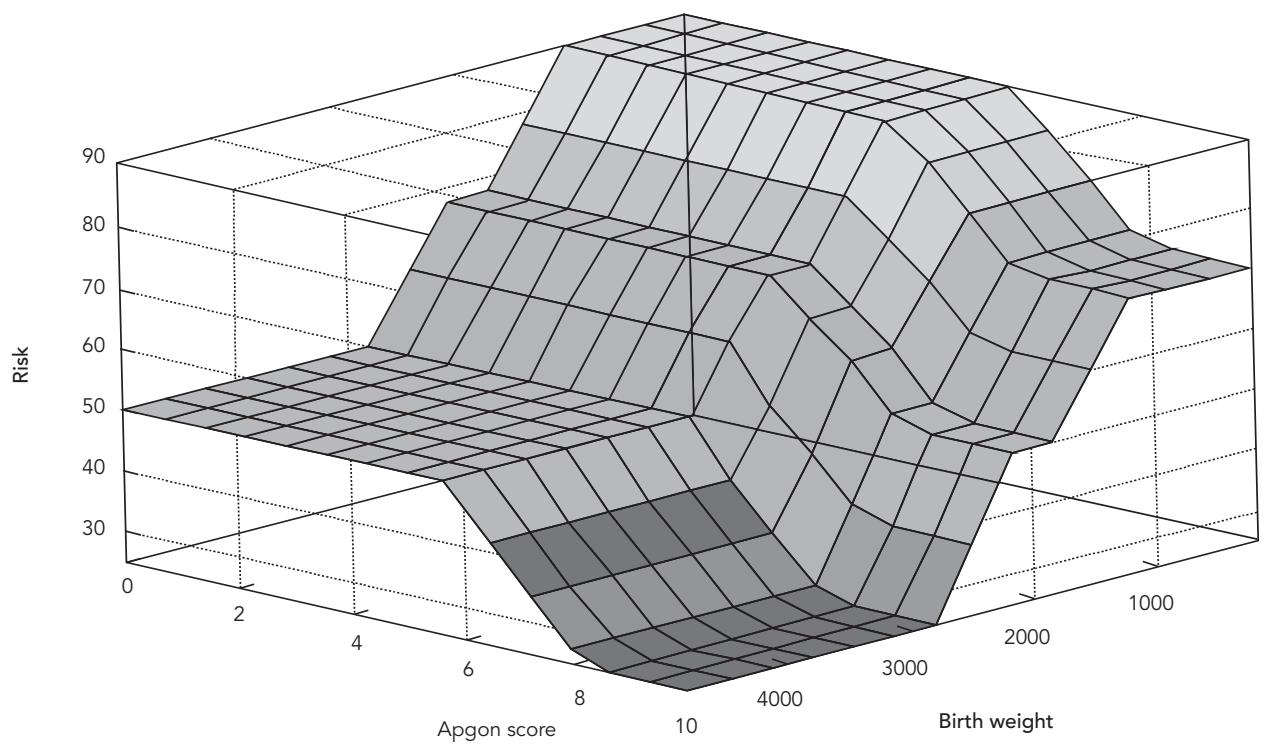

from different geographic locations. It is common to get different answers from experts for the same question in a week's time. In this sense, the model presented here could offer a standardization of the classification process. On the contrary, our model did not use several blood analyses as is the case for PRISM, SNAP and CRIB.

In addition, this model prevents the variability in the analysis of newborn conditions provided by different health professionals, which could yield inequalities in the treatment. Besides, the fuzzy model is very simple and involves low costs in terms of computing, making it an easy and inexpensive option, factors that are particularly relevant in developing and poor countries.

On the other hand, it is not possible to compare this model with other predictive models because the fuzzy model does not use blood analyses and current models such as PRISM, SNAP or CRIB do not use the fuzzy variables.

In cities where there are no experts available, the model can help understanding and evaluating the risk of neonatal death based only on information regarding the birth weight Apgar score, previous report of stillbirth and gestational age without the need for laboratory tests and the value obtained immediately after the birth. This is available even in very modest conditions.
A similar model was developed based only on expert opinions with agreements 4 .

On the other hand, it is important to bear in mind that the number of fuzzy rules grows exponentially and this can impair the model's performance. Besides, the inclusion of new variables does not guarantee the improvement and robustness of the model.

The application of fuzzy sets theory in medicine and, particularly, in pediatrics, is a new area of research. Nevertheless, this approach has provided promising results in several medical applications, proposing a paradigmatic shift in health sciences 2,12 . The possibility of building a computational interface makes this fuzzy model a promising and useful predictive tool. 
ROC curve in respect to fuzzy model.

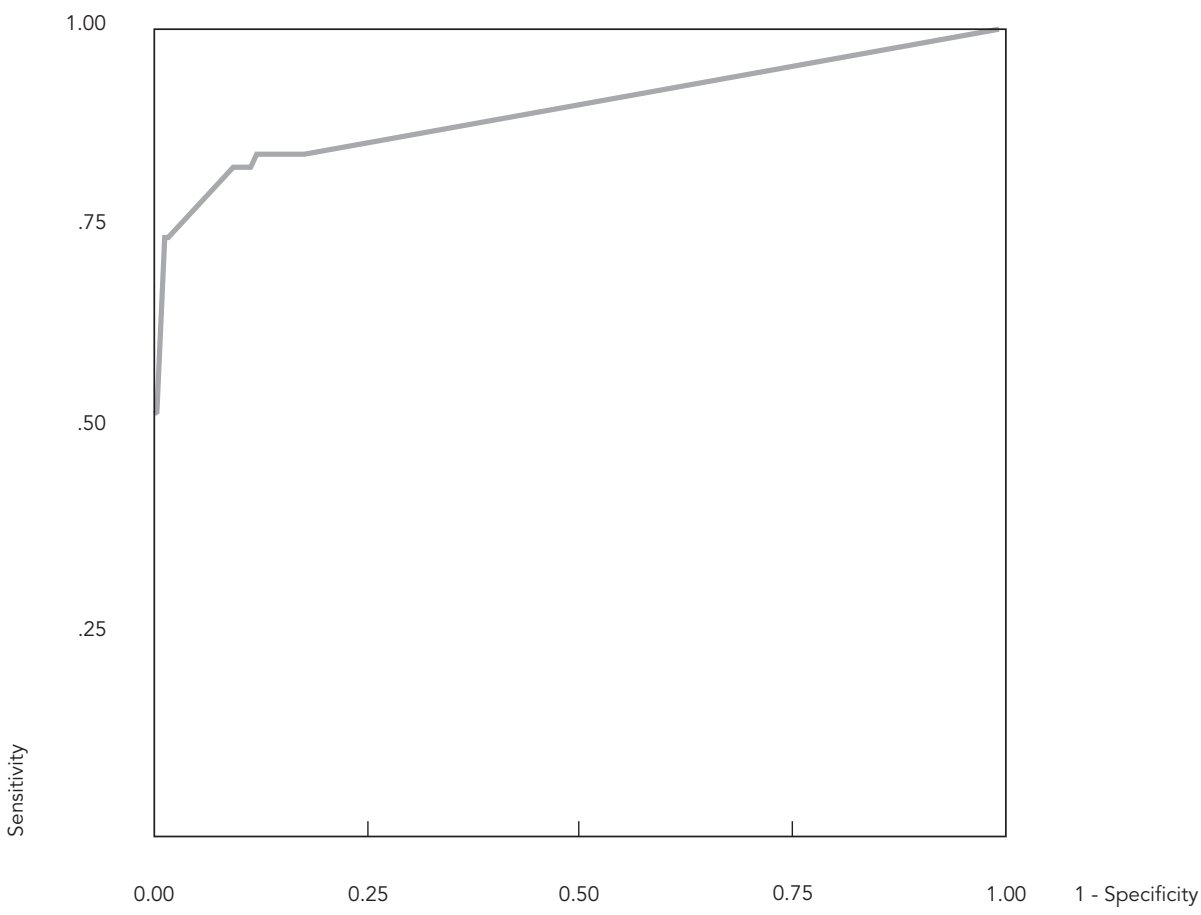

\section{Resumo}

O objetivo do artigo foi avaliar o uso da lógica fuzzy para estimar possibilidade de óbito neonatal. Desenvolveu-se um modelo computacional com base na teoria dos conjuntos fuzzy, tendo como variáveis peso ao nascer, idade gestacional, escore de Apgar e relato de natimorto. Empregou-se o método de inferência de Mamdani, e a variável de saída foi o risco de morte neonatal. Criaram-se 24 regras de acordo com as variáveis de entrada, e a validação do modelo utilizou um banco de dados real de uma cidade brasileira. A acurácia foi estimada pela curva ROC; os riscos foram comparados pelo teste t de Student. O programa MATLAB 6.5 foi usado para construir o modelo. Os riscos médios foram menores para os que sobreviveram $(p<0,001)$. A acurácia do modelo foi 0,90. A maior acurácia foi com possibilidade de risco igual ou menor que 25\% (sensibilidade $=0,70$, especificidade $=0,98$, valor preditivo negativo $=0,99$ e valor preditivo positivo $=0,22) . O$ modelo mostrou acurácia e valor preditivo negativo bons, podendo ser utilizado em hospitais gerais.

Mortalidade Neonatal; Lógica Fuzzy; Computação em Informática Médica; Fatores de Risco; Valor Preditivo dos Testes

\section{Contributors}

All authors participated equally in the study. 


\section{References}

1. Sadegh-Zadeh K. Fuzzy genomes. Artif Intell Med 2000; 18:1-28.

2. Sousa CA, Duarte PS, Pereira JCR. Fuzzy logic and logistic regression in the decision making for parathyroid scintigraphy study. Rev Saúde Pública 2006; 40:898-906.

3. Adlassnig K-P. Proceedings of Erudit Workshop Fuzzy Diagnostic and Therapeutic Decision Support. Vienna: Österreichishe Computer Gessellschaft; 2000.

4. Ortega NRS, Sallum PC, Massad E. Fuzzy dynamical system in epidemic modelling. Kybernetes 2000; 29:201-18.

5. Nascimento LFC, Ortega NRS. Fuzzy linguistic model for evaluating the risk of neonatal death. Rev Saúde Pública 2002; 36:686-92.

6. Abrams B, Newman V. Small for gestational age birth: maternal predictors and comparison with risk factors of spontaneous preterm delivery in the same cohort. Am J Obstet Gynecol 1991; 164:785-90.
7. Menezes AMB, Barros FC, Victora CG, Tomasi E, Halpern R, Oliveira ALB. Fatores de risco para mortalidade perinatal em Pelotas. Rev Saúde Pública 1998; 32:209-16

8. Yen J, Langari R. Fuzzy logic: intelligence, control and information. Upper Saddle River: PrenticeHall; 1999.

9. Pollack MM, Ruttiman EU, Getson PR. Pediatric risk of mortality (PRISM) score. Crit Care Med 1988; 16:1110-6.

10. Richardson DK, Gray JE, McKormick MC, Workman K, Goldmann DA. Score for neonatal acute physiologic severity index for neonatal intensive care. Pediatrics 1993; 91:617-23.

11. International Neonatal Network. The CRIB (critical risk index for babies) score: a tool for assessing initial neonatal risk and comparing performance of neonatal intensive care units. Lancet 1993; 342:193-8.

12. Sadegh-Zadeh K. Fundamentals of clinical methodology: 3. Nosology. Artif Intell Med 1999; 17:87108.

Submitted on $23 / \mathrm{Jul} / 2008$

Final version resubmitted on 09/Mar/2009

Approved on 11/May/2009 